\title{
Relevance of Measuring Substances in Bronchoalveolar Lavage Fluid for Detecting Aspiration-associated Extraesophageal Reflux Disease
}

TO THE EDITOR: We read with great interest the paper by Özdemir et $\mathrm{al}^{1}$ on the assay of lipid-laden macrophages (LLMs) in broncho-alveolar lavage (BAL) fluid of patients with chronic cough as a marker of micro-aspiration of refluxate into airways. The authors found that patients with abnormal extra-esophageal reflux as measured by 24-hour impedance-pH monitoring had higher LLM positivity in BAL specimens than those with normal reflux and, accordingly, they suggested that this BAL finding should be used to diagnose aspiration in reflux-related chronic cough.

The measurement of LLMs from BAL specimens is one of the most widely used tests to identify aspiration-associated extraesophageal reflux disease (AERD), particularly in children. ${ }^{2}$ This test is based on the hypothesis that the refluxate is phagocytosed by alveolar macrophages and that staining for those in the BAL fluid would verify the presence of AERD. However, previous studies have demonstrated conflicting results, because an increase in LLMs has been observed not only in reflux patients, but also in those without reflux and in any disorder leading to pulmonary inflammation. ${ }^{3,4}$

On the other hand, search for pepsin and bile acids in BAL has been shown to represent a more valid and specific biomarker of micro-aspiration in patients with objective evidence of abnormal reflux burden since, up to now, no studies have measured their presence in BAL of healthy volunteers or in patient-controls without evidence of reflux disease. ${ }^{5}$ Thus, the detection of the above substances in BAL has been considered overall as a strong confirmation of gastric contents coming up from the stomach into the airways.

Ozdemir et $\mathrm{al}^{1}$ stated that BAL pepsin levels have been studied very poorly to diagnose gastroesophageal reflux (GERD) in patients with respiratory symptoms and quote the only investigation by Decalmer et al, ${ }^{6}$ in which the authors found in controls lower levels of pepsin than those detected in chronic cough patients. However, it must be emphasized that in this study various respiratory conditions beyond GERD were considered to elucidate the presence of unexplained chronic cough and this may have been an important confounding factor.

In our laboratory the detection of pepsin and bile acids in BAL of patients with GERD was also performed in a recent study ${ }^{7}$ using impedance-pH monitoring, which is nowadays considered to be the best test for measuring gastroesophageal reflux, also in cases of atypical manifestations of GERD. ${ }^{8-10}$ We found that patients with idiopathic pulmonary fibrosis had significantly higher esophageal acid exposure and greater number of acid refluxes than controls, but also that weakly acidic refluxes were remarkably increased. Moreover, more bile acids and pepsin were measured in BAL as a sound marker of gastric aspiration in the upper airways of these patients. Further studies carried out in patients with various pulmonary conditions corroborated our findings. ${ }^{11,12}$

So far, we would like to emphasize that the detection of various substances in BAL can be of great help in the diagnosis of microaspiration of refluxate which is able to induce chronic cough and other respiratory symptoms, but the assay of bile acids or pepsin levels seems to provide us with a more valid and reliable marker of contents reaching the larynx and pharynx from the stomach.

Edoardo Savarino, ${ }^{1}$ Patrizia Zentilin, ${ }^{2}$ Elisa Marabotto, ${ }^{2}$ and Vincenzo Savarino ${ }^{2}$

${ }^{1}$ Division of Gastroenterology, Department of Surgery, Oncology and Gastroenterology, University of Padua, Padua, Italy; and ${ }^{2}$ Division of Gastroenterology, Department of Internal Medicine, University of Genoa, Genoa, Italy 
1. Özdemir P, Erdinç M, Vardar R, et al. The role of microaspiration in the pathogenesis of gastroesophageal reflux-related chronic cough. J Neurogastroenterol Motil 2017;23:41-48.

2. Kelly EA, Parakininkas DE, Werlin SL, Southern JF, Johnston N, Kerschner JE. Prevalence of pediatric aspiration associated extra-esophageal reflux disease. JAMA Otolaryngol Head Neck Surg 2013;139:9961001.

3. Ahrens P, Noll C, Kitz R, Willigens P, Zielen S, Hofmann D. Lipidladen alveolar macrophages (LLAM): a useful marker of silent aspiration in children. Pediatr Pulmonol 1999;28:83-88.

4. Kitz R, Boehles HJ, Rosewich M, Rose MA. Lipid-laden alveolar macrophages and $\mathrm{pH}$ monitoring in gastroesophageal reflux-related respiratory symptoms. Pulm Med 2012;2012:673637.

5. Farrell S, Mcmaster C, Gibson D, Shields MD, McCallion WA. Pepsin in bronchoalveolar lavage fluid: a specific and sensitive method of diagnosing gastro-oesophageal reflux-related pulmonary aspiration. J Pediatr Surg 2006;41:289-293.

6. Decalmer S, Stovold R, Houghton LA, et al. Chronic cough: relationship between microaspiration, gastroesophageal reflux, and cough frequency. Chest 2012;142:958-964.

7. Savarino E, Carbone R, Marabotto E, et al. Gastroesophageal reflux and gastric aspiration in idiopathic pulmonary fibrosis patients. Eur Respir J 2013;42:1322-1331.
8. Zentilin P, Dulbecco P, Savarino E, Giannini E, Savarino V. Combined multichannel intraluminal impedance and $\mathrm{pH}$-metry: a novel technique to improve detection of gastroesophageal reflux: literature review. Dig Liver Dis 2004;36:565-569.

9. Ribolsi M, Savarino E, De Bortoli N, et al. Reflux pattern and role of $\mathrm{pH}$-impedance variables in predicting PPI response in patients with suspected GERD-related chronic cough. Aliment Pharmacol Ther 2014;40:966-973.

10. de Bortoli N, Nacci A, Savarino E, et al. How many cases of laryngopharyngeal reflux suspected by laryngoscopy are gastroesophageal reflux disease-related? World J Gastroenterol 2012;18:4363-4370.

11. Strugala V, Woodcock AD, Dettmar PW, Faruqi S, Morice AH. Detection of pepsin in sputum: a rapid and objective measure of airways reflux. Eur Respir J 2016;47:339-341.

12. Hayat JO, Yazaki E, Moore AT, et al. Objective detection of esophagopharyngeal reflux in patients with hoarseness and endoscopic signs of laryngeal inflammation. J Clin Gastroenterol 2014;48:318-327.

\section{Conflicts of interest: None.}

Author contributions: Edoardo Savarino, Patrizia Zentilin, Elisa Marabotto, and Vincenzo Savarino: planning the study, interpreting data, writing of the manuscript and approving final version. 